\title{
Research on Cultivating Students' Innovative Ability in College Physical Education based on Knowledge Graph
}

\author{
Ping Luo \\ Yichun Vocational Technology College, Yichun 336000, China \\ 3066412763@sina.com
}

\begin{abstract}
As a new learning method rooted in the Internet and big data, knowledge graph can exercise people's sensitivity and activity of thinking, and plays an important role in cultivating students' innovation ability. However, at present, there are few studies on the combination of knowledge graph and innovation ability. Therefore, this study chooses to combine knowledge graph with college physical education (P.E.) students' innovation ability to carry out research in the field of education. In college P.E., by analyzing the factors that restrict the cultivation of students' innovative ability, this paper puts forward some methods to cultivate students' innovative ability, such as changing educational concepts, innovating teaching contents and teaching methods, adjusting evaluation methods, and innovating teaching modes, to make students become high-quality talents with all-round physical and mental development and the needs of modern society. Therefore, it is necessary to continuously deepen the educational reform, so that students can continuously improve their interest in P.E. and their innovative ability can be stimulated to a greater extent.
\end{abstract}

Keywords: Knowledge Graph; College P.E; Innovation Ability.

\section{Introduction}

As the essence and important component of human knowledge system, scientific and technological knowledge has its own unique laws of existence, development and evolution, and the theoretical knowledge system of studying youth sports as an organic part of scientific knowledge is of course no exception [1]. Higher education shoulders the responsibility and obligation of cultivating and cultivating talents with innovative abilities for the society. As an important part of college teaching, P.E. is the unshirkable responsibility of every college P.E. teacher to strengthen the cultivation of students' innovative ability [2]. The reform of college P.E. teaching content should meet the needs of social development, the needs of college students for comprehensive physical exercise, and the needs of college students with low P.E. foundation and poor teaching conditions [3]. The reform of teaching content should focus on non-competitive sports, pay attention to comprehensive fitness of sports, enhance students' lifelong sports awareness and cultivate the ability of various sports. P.E. teaching in Colleges and universities should be comprehensive in content and diverse in methods, especially highlighting the characteristics of fitness, practicality, lifelong, entertainment and initiative. The construction of teaching content can enable students to actively participate in physical exercise, enjoy the happiness brought by physical exercise and cultivate the awareness of lifelong physical exercise [4]. Under the background of the new curriculum reform, colleges and universities require that the construction of P.E. teaching content can cultivate college students' higher, more flexible and more comprehensive innovation ability. In college P.E., teachers should give full play to students' subjective initiative, change students' roles to become masters of learning, and students can actively participate in classroom teaching, cultivate divergent thinking and better cultivate students' innovative ability [5]. This paper studies how to cultivate students' innovative ability in P.E. in colleges and universities by summarizing the theory of knowledge graph and combining the investigation and exploration of papers on the construction of P.E. content in recent years. 


\section{Knowledge Graph and the Concept of Sports Innovation}

\subsection{The Concept of Knowledge Graph}

The concept of knowledge map was put forward by Google. On May 17, 2012, Google announced the knowledge map project, and announced that it would build the next generation intelligent search engine on this basis. The famous ones in China are Baidu Zhixin and sogou Litchi [6].

Then, scholars and experts at home and abroad can't reach a unified conclusion about what is knowledge map. Wikipedia's interpretation of knowledge map terms still follows Google's definition. In other words, knowledge map is the auxiliary knowledge base of search engine function. However, this explanation is obviously too simplistic. According to Liu Qiao, "Knowledge Map is a structured semantic knowledge base, which is used to describe concepts and relationships in the physical world in the form of symbols. The related attribute value pairs are linked with entities through relationships to form a network knowledge structure. "Xu Zenglin and others believe that knowledge map is essentially" a semantic network that represents the relationship between real world objects and entities, and can formally describe the relationship between them". Qi Guilin said, "Knowledge map is essentially a knowledge base called semantic network, that is, a knowledge base with a directed graph structure, in which the nodes of the graph represent entities or concepts and the edges of the graph represent entities. Concepts. Semantic relations between two entities of the same kind "[7]. It can be seen that the knowledge map has been developed for more than 10 years. Although everyone focuses on the knowledge map when interpreting it, there is no essential difference. In other words, knowledge map is a series of graphs showing the development process of knowledge and its structural relations. It uses visualization technology to describe knowledge resources and their carriers, and mines, analyzes, constructs, derives and analyzes knowledge and their mutual relations.

\subsection{Concept of Sports Innovation}

Innovation means to improve based on the original, and can achieve certain results. Therefore, sports innovation is to carry out theoretical or technical transformation or research and development on the basis of the original sports activities, and to achieve a certain degree of meaningful innovation activities. Of course, sports innovation is limited to sports [8].

Figure 1 shows the innovative ability training scheme of the integration of production and education, which includes four aspects.

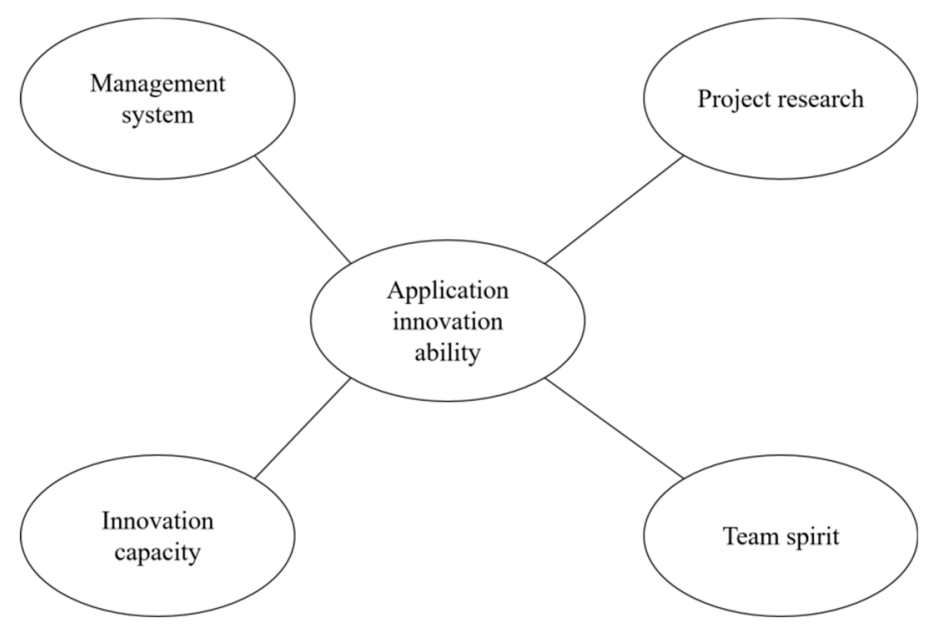

Figure 1. Innovation ability training program

The discussion about the positioning of college P.E. goals has never stopped since the founding of New China. The scale and length of time are unique in other countries. According to literature statistics, the goals of P.E. in colleges and universities are mainly concentrated in the following areas, as shown in Table 1. It can be seen from Table 1 that P.E. does have multiple functions. But education is a staged activity, and each stage has its specific tasks and focuses. 
Table 1. P.E. teaching goals in colleges and universities

\begin{tabular}{|c|c|}
\hline Kind & Focus \\
\hline Improve health, strengthen physical fitness & Learn and master sports knowledge and skills \\
\hline Improve the level of competitive sports & Cultivate students' physical ability \\
\hline Entertainment and sports interests & Lifelong P.E. \\
\hline Improve the quality of sports culture & Use sports as a means to cultivate good morals \\
\hline Promote the common development of body and mind & Master the exercise method \\
\hline
\end{tabular}

Innovation is the inheritance power of a country and society. Science and technology continue to make achievements in R \&amp; D in innovation and create valuable products for mankind. Innovation has enabled the continuous development of the economic level and is approaching a well-off society in an all-round way. These are all because of innovation. The cultivation of innovation ability in college students' P.E. teaching needs the innovation of P.E. learning. The most important thing is the innovation of education system, which is the starting point of knowledge dissemination [9]. P.E. is an important course in Colleges and universities. We should pay more attention to the cultivation of College Students' innovative ability in P.E. learning. The innovative teaching of P.E. not only requires students to learn, but also requires students to produce new ideas in the process of learning, give full play to their potential and stimulate students' innovative thinking ability.

\section{Cultivation of Innovative Ability of College P.E. Students based on Knowledge Graph}

Psychological research holds that cultivating students' creative ability is to cultivate students' creative personality and divergent thinking. Creative personality includes independence, selfconfidence, curiosity, taking risks, expressing desire, fantasy, sensitivity, sense of humor and so on. Divergent thinking refers to students' active thinking and association radiating around the theme when they start thinking activities. The specific structure diagram is as follows:

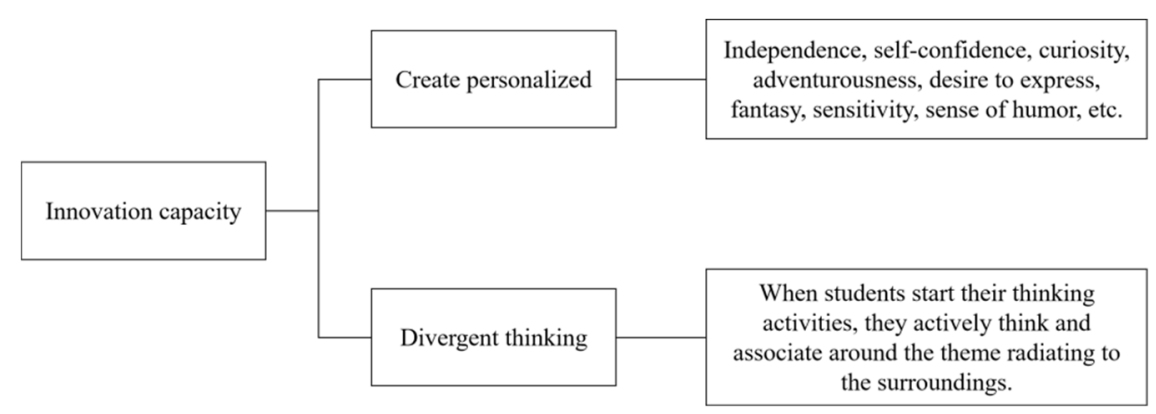

Figure 2. Structure diagram of innovation capability

Since the current application of the knowledge graph is mostly concentrated in the Internet field, it seems difficult to find an entry point for teaching in colleges and universities, but the presentation form of the knowledge graph-graphics, is like another technology that has now been used in middle school teaching-mind mapping. The same works are different. It can be said that the knowledge graph is a mind map of artificial intelligence and a data version of mind map.

Knowledge graph itself is a subject knowledge management system. Its construction must follow the specific knowledge structure, such as the same logic as the textbook. However, due to the attributes of its search engine and its unique graphic structure, it can present the subject knowledge in different forms in front of students. Through the learning of knowledge graph, students can clarify the hierarchical relationship between knowledge without being limited by the logic of teaching materials, and build their own comprehensive knowledge structure in continuous exploration.

P.E. is a practical course. Teachers use existing teaching facilities to give correct guidance and effective teaching. This will stimulate students' interest in sports and improve their learning efficiency. Give full play to the teaching equipment in colleges and universities, and use projection courseware 
to show the difficulties and key points in ordinary teaching and carry out effective teaching. First of all, we should pay more attention to P.E. By holding lectures on sports health knowledge and setting corresponding goals, students can realize the importance of sports in essence and the important relationship between sports and their own growth and health. In addition, with a clear goal, it is easy to stick to it happily when accepting P.E. lessons. Secondly, we must actively exert our own subjective initiative in the teaching process. To make students realize this change, they must realize their role in P.E. As college students in the new era, they should improve their own quality in all aspects. Physical health quality is an important aspect. In the improvement of physical health quality, college students are the main body and teachers are facilitators. College students should play their own subjective initiative to learn actively, Active thinking.

The examination and evaluation of students' learning effect has always been an important factor affecting students' learning direction. Paying too much attention to the examination results and fixed examination forms has always been the biggest disadvantage of the traditional "examination-oriented education". Reform the traditional examination and evaluation methods, flexibly master the examination methods according to the actual situation of students, and do not rigidly specify the examination items. The technical subjects are mainly students' self-selected items, which are mainly evaluated and scored according to the specific situation of students before and after learning. Theory is in the form of homework. Students choose relevant sports topics to create at will, and then make appropriate evaluation according to the value, significance and depth of the article, so as to promote students' innovation ability to be truly improved.

\section{Conclusion}

Innovation is an important part in the development of P.E. in colleges and universities. In teaching, all teachers need to make constant efforts to explore new teaching ways and methods. According to the needs of social development, the cultivation of innovative consciousness and ability should be carried out throughout P.E., and students' interest in learning should be stimulated through project innovation, system innovation and competition innovation, to enable students to establish correct learning concepts, cultivate sports awareness, improve sports literacy and develop the habit of lifelong exercise, so as to make their body and mind develop in an all-round way. P.E. should keep improving with the pace of the times, not only to meet the requirements of today's P.E., but also to meet the needs of students for learning and growth. Colleges and universities should face up to the teaching status quo of public P.E. courses and take effective measures to solve them. As the organizer of P.E., teachers should be responsible for the teaching to students, strive to optimize P.E., and promote the all-round development of students. Knowledge graph can not only improve students' sports achievements, but also promote the cultivation of students' innovative ability. Applying the theory and method of knowledge graph to cultivate students' innovative ability in college P.E. requires not only rich professional P.E. knowledge reserve, but also related theories and methods of knowledge graph as support, which is a brand-new and challenging subject. Therefore, it is inevitable that there will be some shortcomings in research.

\section{References}

[1] Zhang Yingchun. Analysis of the status quo and hot spots of my country's college P.E. teaching research under the scientific knowledge graph[J]. Sports Science and Technology Literature Bulletin, 2017, 25 (010): 122-125.

[2] Jiang Min, Zhang Chunhe. Analysis of research hotspots of sports innovation ability based on citespaceIII [J]. Journal of Hubei Normal University (Philosophy and Social Sciences Edition), 2017, 03 (No.407): 87-91.

[3] Zhang Zhaolong [1], Zhou Liyun [1]. Analysis on the cultivation of students' innovative ability in P.E. classroom teaching in colleges and universities[J]. Sports World (Academic Edition), 2018, 781(07):181182. 
[4] Qian Qian. Suggestions on the cultivation of innovative P.E. and students' innovative ability in colleges and universities [J]. Business Intelligence, 2020, 000(021):226-227.

[5] Zhang Ming. Discussion on the cultivation of students' innovative ability in college P.E.[J]. Contemporary Sports Science and Technology, 2020, 010(012):96-97.

[6] Zhang Jian, Wang Jiwei. Knowledge graph analysis of research on P.E. teacher education in my country[J]. Journal of Henan Normal University: Natural Science Edition, 2018, 046(001):118-124.

[7] Dong Shibiao. An analysis of the frontiers and theoretical evolution of P.E. teaching research in my country's colleges and universities from the perspective of a knowledge graph [J]. Stationery \& Sports Articles \& Technology, 2019, 000(014):159-160.

[8] Jiang Jianzhong. Analyze how to cultivate students' innovative ability in college P.E.[J]. Contemporary Sports Science and Technology, 2018, 8(36):118-119.

[9] Yang Xiaocui. Exploration of the elements of innovative P.E. teaching and the cultivation of students' innovative ability in colleges and universities [J]. Contemporary Sports Science and Technology, 2019, 009 (010):177-178. 